\title{
A sprayable Acid-Oxidizing solution containing hypochlorous acid (AOS2020) efficiently and safely inactivates SARS-Cov-2: a new potential solution for upper respiratory tract hygiene
}

\author{
Nadia Giarratana ${ }^{1}$ D $\cdot$ Balan Rajan $^{2} \cdot$ Kannan Kamala $^{2} \cdot$ Michelle Mendenhall $^{3} \cdot$ Giorgio Reiner $^{1}$
}

Received: 2 November 2020 / Accepted: 21 January 2021 / Published online: 11 February 2021

(c) The Author(s) 2021

\begin{abstract}
Introduction To eliminate the COVID-19 pandemic, the transmission of the virus SARS-CoV-2 among the population needs to be blocked and/or at least reduced. Upper respiratory tract viral loads are highest in the early stages of the disease, and high loads are associated with higher mortality rates. This study aims to evaluate the virucidal efficacy of AOS2020, a novel sprayable Acid-Oxidizing solution containing pure and stable hypochlorous acid ( $\mathrm{HClO}$ ), on human coronavirus SARS-Cov-2 in vitro, and the tolerability profile on nasal and oral mucosa suggesting to be a potential solution for upper respiratory hygiene.

Method Virucidal assays and intranasal and oral irritation tests were undertaken in accordance with relevant national and international guidance and methods.

Results In pre-clinical tests, the AOS2020, showed $>99.8 \%$ virucidal efficacy in $<1$ min against SARS-Cov-2. The safety profile testing on both the nasal and oral mucosa indicates that AOS2020 is non-irritant.

Conclusion These initial results indicate that this product has the potential treatment to reduce viral load in the upper respiratory tract.
\end{abstract}

Keywords Hypochlorous acid (HClO) $\cdot$ SARS-CoV-2 $\cdot$ Acid-Oxidizing solution (AOS2020) · Viral load · Upper respiratory tract

\begin{tabular}{|c|c|}
\hline \multicolumn{2}{|c|}{ Abbreviations } \\
\hline AOS & $\begin{array}{l}\text { Acid-Oxidizing solution containing } \\
\text { hypochlorous acid }\end{array}$ \\
\hline CCID50 & $50 \%$ Cell culture infectious dose \\
\hline COVID-19 & Coronavirus disease-2019 \\
\hline CPE & Viral cytopathic effect \\
\hline $\mathrm{HClO}$ & Hypochlorous Acid \\
\hline $\mathrm{MAD}^{\circledR}$ & Mucosal atomization device \\
\hline MERS CoV & $\begin{array}{l}\text { Middle east respiratory syndrome corona- } \\
\text { virus infection }\end{array}$ \\
\hline LRV & Log reduction value \\
\hline ORP & Oxidative reduction potential \\
\hline
\end{tabular}

Nadia Giarratana

nadia.giarratana@apr.ch

1 APR Applied Pharma Research S.A, 6828 Balerna, Switzerland

2 Eurofins Advinus Limited, Bengaluru, India

3 Institute for Antiviral Research, Utah State University, Logan, Utah, USA

\begin{tabular}{|c|c|}
\hline RNA & Ribonucleic acid \\
\hline SARS CoV2 & $\begin{array}{l}\text { Severe acute respiratory syndrome corona- } \\
\text { virus } 2\end{array}$ \\
\hline UV & Ultraviolet light \\
\hline WHO & World Health Organization \\
\hline
\end{tabular}

\section{Background}

The current COVID-19 pandemic is caused by the SARS$\mathrm{CoV}-2$, a human coronavirus and is transmitted primarily through [1]:

- Transfer of infectious pathogen saturated respiratory droplets to mucosal surfaces of a recipient, by sneezing, coughing or speaking

- Fomites-contaminated objects such as surfaces and inanimate objects transfer infection when touched

However, those who are infected yet asymptomatic or those who are pre-symptomatic, are potential sources of 
infection, [2] with modelling suggesting pre-symptomatic transmission of $44 \%$, [3] and real-time data showing $30 \%$ [4] and 54\% infection rates [5] from such carriers.

Initially, the highest viral loads are found in the upper respiratory tract $[6,7]$ in diagnosed patients. The World Health Organization (WHO) guidelines recommend covering the nose and mouth, social distancing and good respiratory and hand hygiene [8]. Thus, treatments which can reduce nasal viral load have the potential to minimize the progression and/or spread of the disease. Nasal-spray treatments for respiratory tract viruses have been explored in pre-clinical and other trials [9-11]. A number of potential COVID-19 treatments products delivered by nasal spray have been explored $[12,13]$. Hypochlorous acid $(\mathrm{HClO})$ is a potent broad-spectrum fast-acting antibacterial agent with a favourable safety profile [14]. In nasal formulations, it has shown bactericidal, fungicidal, or virucidal effects $[15,16]$.

A unique Acid-Oxidizing solution (AOS2020) containing pure and stable $\mathrm{HClO}$ in a liquid carrier solution [Tehclo Technology ${ }^{\mathrm{TM}}$ APR Applied Pharma Research (APR) SA] comprises a hypotonic solution with unique physicochemical characteristics in terms of $\mathrm{pH} 2.5-3$, oxidative reduction potential (ORP) 1000-1200 mV and free chlorine species of which pure $\mathrm{HClO}$ is not less than $95 \%$. The solution has been already tested for several toxicological parameters such as cytotoxicity on fibroblasts, phototoxicity, genotoxicity, vaginal, systemic and ocular irritation in acute and chronic (data on file). This study evaluated the virucidal efficacy of AOS2020 on human coronavirus SARS-Cov-2 in vitro and the tolerability profile on nasal and oral mucosa suggesting to be a potential solution for upper respiratory hygiene.

\section{Methods}

\section{Virucidal assays}

The USA_WA1/2020 strain of SARS-CoV-2 was obtained from the World Reference Center for Emerging Viruses and Arboviruses (WRCEVA) at the University of Texas Medical Branch (UTMB, Galveston, TX). A working stock of the virus was prepared by passaging the virus in Vero 76 cells. Test media used was MEM supplemented with $2 \%$ FBS and $50 \mu \mathrm{g} / \mathrm{mL}$ gentamicin. The AOS2020 sample was tested at full strength, adding $90 \%$ sample to $10 \%$ virus solution by volume to achieve a final test concentration of $90 \%$ in triplicate. Water was tested in parallel to serve as the virus control. Neutralization and cytotoxicity controls were tested to ensure that virus inactivation did not continue after the specified contact time, and that residual sample in the titer assay plates did not inhibit growth and detection of surviving virus.
The AOS2020 and virus were incubated at room temperature for two contact times of $<1 \mathrm{~min}$ or $3 \mathrm{~min}$, followed by $1 / 10$ dilution in test media containing $10 \%$ FBS to neutralize. For virus quantification, triplicate neutralized samples from each time point were pooled then serially diluted using eight half-log dilutions in test medium. Each dilution was added to $80-100 \%$ confluent Vero 76 cells. On day 6, postinfection plates were scored for presence or absence of viral cytopathic effect (CPE). The Reed-Muench method was used to determine end-point titers (50\% cell culture infectious dose, CCID50) of the samples, and the log reduction value (LRV) of the compound compared to the negative (water) control was calculated.

\section{Intranasal irritation test}

This study was performed in an Association for Assessment and Accreditation of Laboratory Animal Care International (AAALAC) accredited laboratory. All procedures were in compliance with the guidelines provided by the Committee for Purpose of Control and Supervision of Experiments on Animals (CPCSEA) Government of India (Registration Number: 2/PO/RcBi/SL/99/CPCSEA) and ISO 10,993-2, Biological evaluation of medical devices-Part 2: Animal welfare requirements. This study plan has been reviewed and approved by the Institutional Animal Ethics Committee (IAEC) of Eurofins Advinus Limited under the Proposal No. 012/Jan-2020 dated 28 January 2020.

The rabbit model has been selected according to the International Standard (ISO 10,993-10) for Medical Device. In addition, the rabbit is often promoted as the prototypical experimental animal as human surrogates in olfaction and inhalation toxicology tests. This is mainly because of the similarities between its sinus anatomy and its immune responses and those of human beings as well as the favourable size of its sinuses and relative ease of access to them [17].

Nine young male New Zealand White Rabbits (not less than $2 \mathrm{Kg}$ in weight) have been divided into 3 groups ( $\mathrm{G} 1=$ control with $0.5 \mathrm{~mL}$ saline, $\mathrm{G} 2=0.2 \mathrm{~mL}$ AOS2020, $\mathrm{G} 3=0.5 \mathrm{~mL}$ AOS2020 for each nostril) administered twice daily for 5 consecutive days. The decision to consider 5 days of treatment derived from the following considerations and to use the preliminary tolerability profile from rabbit model to support a clinical trial and the final use of the product in humans:

- Once a person is infected exist the 'latent period' before be able to transmit the virus. The current best-estimate of the median latent time is $\approx 3$ days followed by $\approx 4$ days of close to maximal infectiousness [3, 18]. Linton et al. showed a median incubation period of 5.1 days (95\% CI 4.5-5.8 days) [19]. 
- The median time from illness onset to hospital admission was approximately 4 days among cases not known to be deceased at the time of the case report, and 6 days among cases reported as deceased [18].

- According to the standard upper respiratory viruses, if symptoms deteriorate after 5 days of onset or persist beyond 10 days, it is likely that there is secondary bacterial infection. This requires a clinician evaluation [20].

The test item has been intranasally applied using a 1-mL syringe fitted with MAD $^{\circledR}$ (Mucosal Atomization Device) at the interval of $4 \mathrm{~h}$. Local reactions at the site of application were examined twice daily on all application days and evaluated as per the method of Draize [21] Histopathological examination has been carried out on the nasal cavity and evaluation's scores were recorded as per method B.3 of ISO 10,993-10 and the irritation index is calculated as per method B.4.of ISO 10,993-10. The experiment has been done in a GLP Laboratory.

\section{Oral irritation test}

Toxicon strictly adhered to the United States Department of Agriculture (USDA), Animal and Plant Health Inspection Service, 9CFR, Guide for the Care and Use of Laboratory Animals of National Research Council, 1996 (NIH), Office for Laboratory Animal Welfare (OLAW), ISO 10,993-2 and Association for the Assessment and Accreditation of Laboratory Animal Care (AALAC) standards in maintaining the animal care and use program.

Six Golden Syrian Hamster has been divided into 2 groups for the administration of $0.5 \mathrm{~mL}$ of the test item (AOS2020) and $0.5 \mathrm{~mL}$ of control (sterile water for injection) for $5 \mathrm{~min}$ repeated each hour for $4 \mathrm{~h}$. Macroscopic (immediately after each dose and $24 \mathrm{~h}$ after the last dosing) and microscopically (with Irritation Index) evaluation has been done.

\section{Results}

\section{Effect of AOS2020 on human coronavirus SARS-Cov2}

Virus titers and log reduction value (LRV) of SARS-CoV-2 following contact with AOS2020 are shown in Table 1.Virucidal activity was exhibited when the solution was tested at $90 \%$ for $<1 \mathrm{~min}$ and $3 \mathrm{~min}$, reducing virus from $3.5 \mathrm{log}$ CCID50 per $0.1 \mathrm{~mL}$ in virus controls to below the limit of detection of $0.7 \operatorname{logs}(>99.8 \%)$.

Neutralization controls demonstrated that residual sample did not inhibit virus growth and detection in the end-point titer assays in wells that did not have cytotoxicity. Positive controls performed as expected, though ethanol was toxic
Table 1 Virucidal efficacy of AOS2020 against SARS-CoV-2 after incubation with virus at $22 \pm 2{ }^{\circ} \mathrm{C}$

\begin{tabular}{lllcl}
\hline & Concentration & Contact time & Virus titer $^{\mathrm{a}}$ & LRV $^{\mathrm{b}}$ \\
\hline AOS2020 & $90 \%$ & $<1 \mathrm{~min}$ & $<0.7$ & $>2.8$ \\
Virus control & $\mathrm{n} / \mathrm{a}$ & $<1 \mathrm{~min}$ & 3.5 & - \\
AOS 2020 & $90 \%$ & $3 \mathrm{~min}$ & $<0.7$ & $>2.8$ \\
Virus control & $\mathrm{n} / \mathrm{a}$ & $3 \mathrm{~min}$ & 3.5 & \\
\hline
\end{tabular}

${ }^{\mathrm{a}} \log 10$ CCID50 of virus per $0.1 \mathrm{~mL}$

${ }^{\mathrm{b}} \mathrm{LRV}$ (log reduction value) is the reduction of virus compared to the virus control

to cells in the $1 / 10$ dilution, limiting the detection of virus to $<1.7 \log$ CCID50 per $0.1 \mathrm{~mL}$.

\section{Tolerability profile}

No clinical signs or pre-terminal deaths were observed in any of the groups and no local reaction was observed during the macroscopic examination at the site of application both at nasal and oral mucosa. The Irritation index has been evaluated on histological samples from oral tissues (the treated cheek pouch) and was determined to be 0.0 indicating that the AOS2020 solution was non-irritant to the buccal tissues of Golden Syrian Hamster.

After 5 consecutive days of nasal treatment, there were no gross lesions in any of the tested animal. The site of application did not reveal any gross findings. The Irritation index on histological samples of nasal mucosa for the $0.2 \mathrm{~mL}$ and $0.5 \mathrm{~mL}$ dose groups were 0 and 0.083 , respectively, indicating that AOS2020 is non-irritant to the nasal mucosa of male New Zealand White Rabbits.

\section{Discussion}

A coronavirus can be inactivated by ultraviolet (UV) light, or heated at $56{ }^{\circ} \mathrm{C}$ for $30 \mathrm{~min}$, and is sensitive to disinfectants such as diethyl ether, $75 \%$ ethanol, chlorine, peracetic acid, and chloroform [22]. Chlorine-releasing agents act on the capsid and the RNA of several types of viruses [23] and $\mathrm{HClO}$ treatments generally render the viral genome irreplicable [24].

The potential effectiveness of free Chlorine species against SARS-CoV-2 for decontamination of equipment and the care environment is acknowledged in guidelines, [25] but no peer-reviewed evidence on the virucidal activity of $\mathrm{HClO}$ against SARS-CoV-2 is currently available. However, as it is widely used as a disinfectant in aquatic, food, non-food, and antiseptic applications, the safety of chlorine and chlorine compounds including hypochlorous acid and its salts, has been well documented. 
COVID-19 is transmitted predominantly via respiratory droplets [26] with higher viral loads detected in the nose than in the throat, [27] and correlating with disease severity [28]. To monitor disease progression and response to treatment, viral load measurements from tissue samples are routinely used [29]. Zou and colleagues [27] reported that patients with COVID-19 with more severe disease requiring intensive care unit admission, had high viral RNA loads at 10 days and beyond after symptom onset [18]. A recent study indicated that viral loads in severe cases were up to 60 times higher than in mild cases, and a positive association between sputum viral load and disease severity, and the risk of disease progression has been detected in 92 patients with COVID-19 [29].

Starting from the above considerations, these preclinical findings suggest that AOS2020 may be effective in treating patients with SARS-Cov-2 infection and by reducing the viral load in the upper respiratory tract to potentially have a role in reducing both the clinical severity of the disease and the spreading of infection. These considerations have to be confirmed with a clinical trial.

It is widely recognized that the simple mechanical instillation of a solution within the nose could reduce the viral/bacterial load [30]. Keeping the nasal cavity clear can enhance the nasal mucosa's ability to resist the effects of infectious agents, inflammatory mediators and irritants [31]. Ludwig et al. demonstrated that the mechanical activity of cleansing using a solution has an ancillary activity against virusus; the significant reduction of viral load in the nasal wash fluids of patients reduced the duration of disease and recurrence of symptoms [32]. In addition, AOS2020 is a hypotonic solution; considering that the concentration of electrolytes is lower than the average concentration of the mucus due to the osmotic effect, it is absorbed by the mucus and reduces its viscosity (softens/ softening the nasal mucus), thus favouring its clearance and removal.

The first antiviral action to block the virus transmission and prevent severe clinical development of the SARS-Cov-2 infection should start from the upper respiratory tract (nose and throat) where the virus starts to replicate into the body. $\mathrm{HClO}$ has been shown to exhibit both antibacterial and virucidal activity, and in this study, we have shown that an Acid-Oxidizing solution (AOS2020) containing pure and stable $\mathrm{HClO}$ has strong virucidal activity against SARS-Cov-2, with high safety profile on the nasal and oral mucosa. The addition of a strong antiviral efficacy, to the mechanical activity of nasal cleansing, potentially represents an easy and efficient treatment in the panoply of potential COVID-19 treatments.

\section{Conclusions}

This study confirms the virucidal efficacy of AOS2020 against SARS-Cov-2 together with a high tolerability profile on nasal and oral mucosa. As in vitro results, they could be considered as positive indicators of potential activity of AOS2020 for nasal and oral treatment of SARS-Cov-2 infection that should be confirmed with a clinical trial.

Acknowledgements The authors thank Patrizia Marzorati, Head of Medical Affairs at APR Applied Pharma Research S.A. (Balerna, Switzerland) for contributing to the manuscript preparation.

Author Contributions Conceptualization, NG, investigations BR, KN, $\mathrm{MM}$; writing — review and editing NG, BR, KN, MM; GR, supervision.

Funding This study was financially supported by APR Applied Pharma Research S.A. (Balerna/Switzerland).

\section{Compliance with ethical standards}

Conflict of interest NG and GR are employees of APR Applied Pharma Research S.A. (Balerna/ Switzerland); BR and KK are employees of Eurofins Advinus Limited, Bengaluru, India and MM is an employee of Utah State University, Institute for Antiviral Research: all of them are contract research organizations, with no financial interest in APR Applied Pharma Research S.A.

Open Access This article is licensed under a Creative Commons Attribution 4.0 International License, which permits use, sharing, adaptation, distribution and reproduction in any medium or format, as long as you give appropriate credit to the original author(s) and the source, provide a link to the Creative Commons licence, and indicate if changes were made. The images or other third party material in this article are included in the article's Creative Commons licence, unless indicated otherwise in a credit line to the material. If material is not included in the article's Creative Commons licence and your intended use is not permitted by statutory regulation or exceeds the permitted use, you will need to obtain permission directly from the copyright holder. To view a copy of this licence, visit http://creativecommons.org/licenses/by/4.0/.

\section{References}

1. World Health Organization (2010) Modes of transmission of virus causing COVID-19: implications for IPC precaution recommendations. https://www.who.int/news-room/commentaries/detail/ modes-of-transmission-of-virus-causing-covid-19-implicationsfor-ipc-precaution-recommendations. Accessed 8 Feb 2021

2. F Huang M, Liang L, Huang H, Hong Z et al (2020) SARS-CoV-2 viral load in upper respiratory specimens of infected patients. $\mathrm{N}$ Engl J Med 382(12):1177-1179

3. He X et al (2020) Temporal dynamics in viral shedding and transmissibility of COVID-19. Nat Med 26:672-675

4. Kimball A, Hatfield KM, Arons M, James A et al (2020) Asymptomatic and presymptomatic SARS-CoV-2 infections in residents of a long-term care skilled nursing facility. MMWR Morb Mortal Wkly Rep 69(13):377-381. https://doi.org/10.15585/mmwr. mm6913e1 (PMID: 32240128; PMCID: PMC7119514) 
5. Arons MM, Hatfield KM, Reddy SC, Kimball A et al (2020) Presymptomatic SARS-CoV-2 infections and transmission in a skilled nursing facility. N Engl J Med 382:2081-2090. https://doi. org/10.1056/NEJMoa2008457

6. He X, Lau EHY, Wu P, Deng X, Wang J, Hao X et al (2020) Temporal dynamics in viral shedding and transmissibility of COVID-19. Nat Med 26:672-675. https://doi.org/10.1038/s4159 1-020-0869-5

7. Jie Wu, Zou L, Ruan F (2020) SARS-COV-2 viral load in upper respiratory specimens of infected patients. N Engl J Med 382:1177-1179. https://doi.org/10.1056/NEJMc2001737

8. World Health Organisation. Coronavirus disease (COVID-19) advice for the public. https://www.who.int/emergencies/diseases/ novel-coronavirus-2019/advice-for-public. Accessed 8 Feb 2021

9. Elwany S, Abdel-Salaam S (2001) Treatment of rhinitis medicamentosa with fluticasone propionate-an experimental study. Eur Arch Otorhinolaryngol 258:116-119

10. Wang HW, Lee JC, Wu PC et al (2019) Effects of montelukast on human nasal mucosa. Eur Arch Otorhinolaryngol 276:761-765

11. Virtanen J, Hokkinen L, Karjalainen M et al (2018) In vitro detection of common rhinosinusitis bacteria by the eNose utilising differential mobility spectrometry. Eur Arch Otorhinolaryngol 275:2273-2279

12. Taylor $P$ (2020) Non-vaccine nasal spray could protect against covid-19. Pharmaphorum. https://pharmaphorum.com/news/nonvaccine-nasal-spray-could-protect-against-covid-19/. Accessed 8 Feb 2021

13. Pianta L, Vinciguerra A, Bertazzoni G et al (2020) Acetic acid disinfection as a potential adjunctive therapy for non-severe covid19. Eur Arch Otorhinolaryngol 277(10):2921-2924. https://doi. org/10.1007/s00405-020-06067-8

14. Wang L, Bassiri M, Najafi R, Najafi K, Yang J, Khosrovi B, Hwong W, Barati E, Belisle B, Celeri C, Robson MC (2007) Hypochlorous acid as a potential wound care agent: part I. Stabilized hypochlorous acid: a component of the inorganic armamentarium of innate immunity. J Burns Wounds 11(6):e5

15. $\mathrm{Hj} \mathrm{K}, \mathrm{Jg} \mathrm{L}, \mathrm{Jw} \mathrm{K}, \mathrm{Hj} \mathrm{C}$ et al (2008) Effects of a low concentration hypochlorous acid nasal irrigation solution on bacteria, fungi and virus. Laryngoscope 118(10):1862-1867. https://doi.org/10.1097/ Mlg.0b013e31817f4d34.Pmid:18677274

16. Shang-Heng W, Lin J-F, Jiang R-S (2018) Antibacterial effect of hypochlorous acid solution on nasal discharge from patients with chronic rhinosinusitis. Int J Otolaryngol 2018:5. https://doi. org/10.1155/2018/8568694

17. Kara CO (2004) Animal models of sinusitis: relevance to human disease. Curr Allergy Asthma Rep 4(6):496-499

18. Liu Y, Yan LM, Wan L, Xiang TX et al (2020) Viral dynamics in mild and severe cases of COVID-19. Lancet Infect Dis 20(6):656657. https://doi.org/10.1016/S1473-3099(20)30232-2 (Epub 2020 Mar 19. PMID: 32199493; PMCID: PMC7158902)

19. Linton NM, Kobayashi T, Yang Y, Hayashi K et al (2020) Incubation period and other epidemiological characteristics of 2019 novel coronavirus infections with right truncation: a statistical analysis of publicly available case data. J Clin Med 9(2):538. https://doi.org/10.3390/jcm9020538 (PMID:32079150; PMCID:PMC7074197)

20. Masood A, Moumoulidis I, Panesar J (2007) Acute rhinosinusitis in adults: an update on current management. Postgrad Med J 83(980):402-408. https://doi.org/10.1136/pgmj.2006.054767
21. Draize JH (1959) Intracutaneous sensitization test on guinea pig. In: Appraisal of the Safety of Chemicals in Food and Cosmetics. Association of Food and Drug Officials of the United States, Austin, Texas

22. Cascella M, Rajnik M, Cuoma A, Dulebohn SC, et al (2020) Features, evaluation, and treatment of coronavirus. In: StatPearls [Internet]. Treasure Island (FL): StatPearls Publishing. https:// www.ncbi.nlm.nih.gov/books/NBK554776/

23. Hakim H, Thammakarn C, Suguro A, Ishida Y et al (2015) Aerosol disinfection capacity of slightly acidic hypochlorous acid water towards newcastle disease virus in the air: an in vivo experiment. Avian Dis 59(4):486-491. https://doi.org/10.1637/11107-04211 5-Reg.1.PMID

24. Wigginton KR, Pecson BM, Sigstam T, Bosshard F et al (2012) Virus inactivation mechanisms: impact of disinfectants on virus function and structural integrity. Environ SciTechnol 46(21):12069-12078. https://doi.org/10.1021/es3029473 (Epub 2012 Oct 26 PMID: 23098102)

25. Block MS, Rowan BG (2020) Hypochlorous acid: a review. J Oral MaxillofacSurg 78(9):1461-1466. https://doi.org/10.1016/j. joms.2020.06.029

26. Yang H, Ji W, Wu W, Chen S, Zhang W et al (2020) Virology, epidemiology, pathogenesis, and control of COVID-19. Viruses 12(4):372. https://doi.org/10.3390/v12040372 (PMID: 32230900; PMCID: PMC7232198)

27. Zou L, Ruan F, Huang M, Liang L, Huang H, Hong Z et al (2020) SARS-CoV-2 viral load in upper respiratory specimens of infected patients. N Engl J Me 382(12):1177-1179

28. Yu X, Sun S, Shi Y, Wang H, Zhao R, Sheng J (2020) SARSCoV-2 viral load in sputum correlates with risk of COVID-19 progression. Crit Care 24(1):170. https://doi.org/10.1186/s1305 4-020-02893-8.PMID:32326952;PMCID:PMC7179376

29. Memish ZA, Al-Tawfiq JA, Makhdoom HQ, Assiri A et al (2014) Respiratory tract samples, viral load, and genome fraction yield in patients with Middle East respiratory syndrome. J Infect Dis 210(10):1590-1594. https://doi.org/10.1093/infdis/jiu292 (Epub 2014 May 15. PMID: 24837403; PMCID: PMC7107391)

30. Ramalingam S, Graham C, Dove J, Morrice L et al (2019) A pilot, open labelled, randomised controlled trial of hypertonic saline nasal irrigation and gargling for the common cold. Sci Rep 9:1015. https://doi.org/10.1038/s41598-018-37703-3

31. Rabago D, Zgierska A (2009) Saline nasal irrigation for upper respiratory conditions. Am FamPhys 80(10):1117-1119 (PMID: 19904896; PMCID: PMC2778074)

32. Ludwig M, Enzenhofer E, Schneider S, Rauch M et al (2013) Efficacy of a carrageenan nasal spray in patients with common cold: a randomized controlled trial. Respir Res 14(1):124. https ://doi.org/10.1186/1465-9921-14-124.PMID:24219370;PMCID :PMC3840586

Publisher's Note Springer Nature remains neutral with regard to jurisdictional claims in published maps and institutional affiliations. 